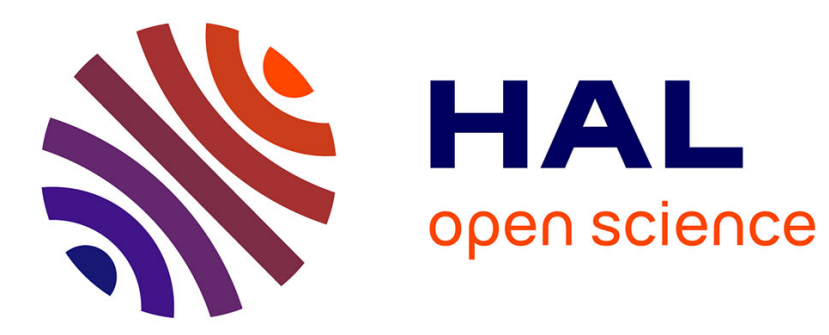

\title{
Interindividual differences in children's knowledge and uses of outdoor public spaces
}

\author{
Alain Legendre, José Gómez Herrera
}

\section{To cite this version:}

Alain Legendre, José Gómez Herrera. Interindividual differences in children's knowledge and uses of outdoor public spaces. PsyEcology. Revista Bilingüe de Psicología Ambiental / Bilingual Journal of Environmental Psychology, 2011, 2 (2), pp.193-206. halshs-00713018

\section{HAL Id: halshs-00713018 https://shs.hal.science/halshs-00713018}

Submitted on 11 Sep 2012

HAL is a multi-disciplinary open access archive for the deposit and dissemination of scientific research documents, whether they are published or not. The documents may come from teaching and research institutions in France or abroad, or from public or private research centers.
L'archive ouverte pluridisciplinaire HAL, est destinée au dépôt et à la diffusion de documents scientifiques de niveau recherche, publiés ou non, émanant des établissements d'enseignement et de recherche français ou étrangers, des laboratoires publics ou privés. 


\title{
Reference of the printed version of the text : \\ Legendre, A., \& Gómez Herrera, J. (2011). Interindividual differences in children's knowledge and uses of outdoor public spaces. Psyechology, 2(2), 193-206.
}

\section{Interindividual differences in children's knowledge and uses of outdoor public spaces}

\author{
Alain Legendre ${ }^{1}$ and José Gómez-Herrera ${ }^{2}$ \\ ${ }^{1}$ Université Européenne de Bretagne - CNRS, UMR 6590 Espaces et Sociétés ; \\ ${ }^{2}$ Universidad Nacional Autónoma de México
}

\begin{abstract}
The focus of this study is on interindividual differences emerging among 6 to 11 yearold children in terms of their knowledge of and the way in which they use outdoor public spaces. A survey was conducted with 378 primary school children in a small town in the outskirts of Paris. A questionnaire was used to ascertain the children's knowledge, frequency of visits, recreational use and independent access to the main outdoor public spaces in their town. The results highlight that in an urban environment, public spaces fulfil an important function for children. As young as six years of age, children demonstrate that they already have an extensive knowledge of the squares, parks and play areas in their nearby urban environment. Most of the known outdoor public spaces are regularly visited and used for play by the children; however their independent access to these places is quite restricted. Independent access to outdoor spaces is the behaviour that shows the clearest evolution with age. However, the most important differences observed in children's knowledge and uses of public spaces are related to gender, in favour of the boys. Manifest differences also emerge between children who live in a house and those who live in a flat, the latter exhibiting a more extensive use of the public spaces in their town.
\end{abstract}

Keywords: Urban environment, public spaces, outdoor play, childhood, gender.

Author's Address: Alain Legendre. ESO UMR 6590. UFR en Sciences Sociales. Université de Rennes II. Place du Recteur Henri Le Moal. 35043 Rennes Cedex (France). Tel.: 33 (0)2 99141888. E-mail: alain.legendre@univ-rennes2.fr 


\section{INTRODUCTION}

Playing in open outdoor spaces is an essential element of childhood. They contribute to the primary mechanism by which children became familiar with and appropriate their physical and social environment (Valentine, 2004). The possibility of accessing outdoor spaces could have extremely beneficially consequences on the development and well-being of children (Meire, 2007). Numerous studies have highlighted the contributions made by outdoor play to the health and emotional equilibrium of children (Bagot, Kuo and Allen, 2007; Veitch, Bagley, Ball, and Salmon, 2006), along with their cognitive, motor and especially social development (Delalande, 2009; Lindstrand, 2005; Stone and Lozon 2004).

Consequently, when examining the development of children aged 6 to 11 living in urban settings, it is important to raise the question of their knowledge and use of public outdoor spaces.

\section{Evolution of playing and games in outdoor spaces in Western societies}

Studies carried out in recent decades in Western countries show that the spatial and temporal distribution of children's activities appears to have changed considerably (Larson and Verma, 1999). Children's activities seem to be increasingly controlled and inscribed within very constrained daily and weekly schedules. Regarding the spatial issue, time restrictions and obligations are manifested by the frequenting of an "archipelago of spaces" without children being able to visit them independently (Karsten and van Vliet, 2006). This implies that children must be accompanied and taken from one area of activity to another by their parents (Bachiri, Després and Vachon, 2008). This evolution translates into an increased distance between the places of children's activities (Witlox and Tindemans, 2006), associated with a reduction of autonomous movement, as well as a decline in the frequenting of nearby public spaces (Hillman, Adams and Whitelegg, 1990; Prezza, 2007). 
Numerous studies carried out in town and cities in the US, Europe and Australia have corroborated this tendency and provide evidence of a growing decline in the frequenting of outdoor public spaces among children (Danic, David, and Depeau, 2010; Spencer and Woolley, 2000). In the Netherlands, this evidence has led Karsten and van Vliet (2006 a) to propose the definition of a new category of children: "indoor children".

Certain Anglo-Saxon authors evoke a marginalization, in other words, a certain exclusion of children and teenagers from the city's public spaces (Lennard and Lennard, 2000). In part this exclusion has favoured shopping malls and centres, which have become places to meet and gather (Vanderbeck and Johnson, 2000). In general, children and teenagers are assigned to spaces especially designed for them: specific play areas in public spaces (skate parks) or institutional or private spaces where their activities are under the supervision of adults (sports clubs, leisure centres, adventure parks...).

To explain this phenomenon, we turn to a series of factors: urban, social, family and technological (mobile phones, Internet, games and video consoles, among others). However, among these factors, parents' representations of the dangers to which children are exposed in public spaces occupy a central role. These dangers are associated with the risks of traffic as well as the social risks represented by bigger children (gangs) or malicious adults (Meire, 2007). Hence, these studies show a tangible evolution that intervenes in the status and representations made by children and parents of outdoor spaces, specifically in relation to the public domain: streets, parks or play areas. It would appear that nowadays, children's outdoor play is deemed to be dangerous, particularly when not supervised by adults (Karsten and van Vliet, 2006 b).

\section{Places for outdoor play}

However, Rasmussen (2004) draws our attention to the fact that a more complex picture appears when we distinguish between places "for" children as conceived by adults, 
and children's places chosen "by" children. Indeed, children prize outdoor spaces for games and playing even if they live in a dense urban environment. For example, in England, Burke (2005) asked school children living in Leeds to photograph their favourite areas for playing. She noted that regardless of where they lived, the photos largely represented outdoor spaces whereas indoor spaces represented less than a third of the photographs taken.

Furthermore, research conducted in various countries indicates that children make use of all kinds of places and settings to engage in their activities (MacDougall, Schiller, and Darbyshire, 2009). Among the places indicated by children as places for play, natural and open spaces occupy a predominant position (Fjørtoft, 2004). According to Blinkert (2004), small natural areas are part of the "action space", which is defined by both an informal character and proximity to children's homes facilitating children's use and appropriation.

These studies have led certain authors to minimize the role of public parks and play areas traditionally allocated to children (Burke, 2005; Rasmussen, 2004; Valentine, 2004). However, when we questioned children aged 6 to 11 about their outdoor play areas, close to half of them cited the public parks in their town as an outdoor play area. Furthermore, although the children's responses show that they occupy a wide variety of different outdoor places, we have also observed that open spaces that are accessible to the public such as public parks, block-parks, gardens in residential estates and playgrounds constitute the majority of places mentioned by the children (Legendre, 2011).

\section{Perspectives and objectives}

This study is framed within the developmental perspective in environmental psychology, which combines the dual approach of child development and of the factors of the physical and social environment likely to modulate the development (Correa and Ruiz, 2008). In environmental psychology, right from the outset, the articulation of environmental and developmental perspectives has been an area of particular interest (Wohlwill, 1980). This 
interest has led to the creation of theoretical models which highlight the dynamic nature of the relationship established between the developing human being and the different environmental systems that structure their living context (Bronfenbrenner and Crouter, 1983; Wachs and Shpancer, 1998).

The developmental perspective invites us to gain a deeper understanding of the evolution of environmental competences, which progressively enable children to use the resources offered by their urban living context with increased autonomy (Pesersen, 1999).

The aim of this article is to ascertain the way in which knowledge and use of outdoor public spaces develops in children aged 6 to 11. Indeed, we know that during this phase of development there are significant advancements in children' cognitive representations of space and in their construction of a geographical space (Spencer, Blades, and Morsley, 1989). Consequently, we aim to determine whether the number of outdoor public spaces known, used and accessed independently by children progressively and steadily increases with age or whether, on the contrary, the development of these environmental skills proceeds by successive stages. We will also examine whether, during this stage of life, knowledge of these spaces and their modes of use evolve in a similar or different way in boys and girls.

In addition, we will examine certain characteristics of the children's living environment, such as the type of home in which they live and the location of the home within the town. 


\section{METHODOLOGY}

\section{Urban context of the study}

The research was conducted in the outskirts of Paris (Île-de-France region), in the small town of Arpajon (10,000 inhabitants. The total population of the administrative division of the region is 40,000 inhabitants). This town is located $31 \mathrm{~km}$ from the centre of Paris, within the boundaries of the Metropolitan area.

Specifically, the town is at the juncture between an urban area and an area of farmland and forest. "Rural spaces" (cropland and woodland areas) occupy 10.1\% of the surface area of the town. "Open urban spaces", essentially constituted by over 20 hectares of parks and gardens, also occupy $10.2 \%$ of the surface area. The town of Arpajon has a built urban area of 79.7\% and a density of 38 inhab/ hectare (IAURIF, 2003). According to the Institute of Urban Planning for the region of Île de France (IAURIF), this town is classified as being on the boundary ${ }^{1}$ between a "dense urban area" and "largely urbanized area". Consequently, by choosing the town of Arpajon, we are able to examine whether the declining frequentation of outdoor spaces reported in the literature is also observed in a medium density urban context which offers numerous possibilities of outdoor play spaces for children.

The census carried out at the time of this research showed that the percentage of individual houses is $24 \%$, whereas collective residential estates account for $74.6 \%$. The population aged over 15 is made up of $11.9 \%$ senior executives and higher intellectual professions; $20.5 \%$ intermediate professionals, artisans, retailers and company managers; and $31.1 \%$ correspond to employees and workers. These figures are similar to those for the region of Île-de-France (INSEE, 2006). In this respect, this town is considered to be within the regional average, and does not correspond in any way to a privileged social setting on the

\footnotetext{
${ }^{1}$ The limits for these indicators correspond to $80 \%$ and 30 inhab/ha respectively.
} 
outskirts of the Parisian agglomeration. It is worth mentioning that at the time of this research, children aged 6 to 10 represented $5.06 \%$ of the population living in Arpajon, namely 452 children, $14 \%$ of which corresponded to foreign children.

\section{Participants}

The research was conducted with almost the entire student population from the two state-run primary schools in the town of Arpajon. The aim was to gather information about their knowledge and use of outdoor public spaces, with the maximum possible number of children aged 6 to 11 residing in the town. Therefore, a questionnaire was administered to 378 school children, representing $83.3 \%$ of the children enrolled at the two schools.

Table I

Sample distribution by age and gender

\begin{tabular}{|c|c|c|c|c|c|c|c|}
\hline \multirow{2}{*}{ Gender } & \multicolumn{6}{|c|}{ Age in years } & \multirow{2}{*}{$\begin{array}{c}\text { Total } \\
\text { by gende }\end{array}$} \\
\hline & 6 & 7 & 8 & 9 & 10 & 11 & \\
\hline Girls & 24 & 44 & 35 & 33 & 39 & 13 & 188 \\
\hline Boys & 28 & 35 & 32 & 41 & 36 & 18 & 190 \\
\hline $\begin{array}{l}\text { Total } \\
\text { by age }\end{array}$ & 52 & 79 & 67 & 74 & 75 & 31 & 378 \\
\hline
\end{tabular}

Table I shows in detail the age and gender distribution of the children who completed the questionnaire. The proportion of girls and boys is similar in relation to the total population and in each age range. Of particular note is the fact that there are no significant differences in the gender and age distribution between the two schools (Gender: $\chi^{2}(1, N=378) 2.06$, ns; Age: $\left.\chi^{2}(5, N=378)=3.12, \mathrm{~ns}\right)$. 


\section{Questionnaire}

The questionnaire was designed for the children to evaluate a sample of 10 places corresponding to outdoor spaces accessible to the public, including the main public spaces in the town. Although 10 places were presented to each child, it is noteworthy that 12 places in total were evaluated. Eight of these places were common to children from both schools, and two places were exclusive to each school. These two places were chosen with a view to better covering the geographic sectors where the children from each school live.

In order to analyze the evolution of responses according to age, the decision was made to keep the content of the questionnaire the same for all age levels within the study population, including for the youngest ones. For this reason, the questionnaire was designed so that it would take a maximum of 20 minutes to complete and the questions were phrased in a very simple way. However, to keep the content of the questionnaire identical for all children, the questionnaire application was adjusted according to the age of the students. Hence, for students aged 9, 10 and 11, questions were answered in class in the form of a questionnaire, whereas for the younger students, the questionnaire was carried out in the form of a guided interview in groups of four students with children aged 7 and 8 , and in groups of two students for children aged 6.

The first part of the questionnaire included questions such as: (a) age, (b) date of birth, (c) home address, and (d) the type of housing (house vs. apartment) where the student lived.

In the second part of the exercise, 10 illustration plates were presented successively corresponding to the 10 places to evaluate. Each illustration plate showed five photographs of a particular place, and they were all organized according to the same format (see Figure 1) 
Figure 1. Example of illustration plate

\section{Aire de Jeux \\ Centre Duhamel}
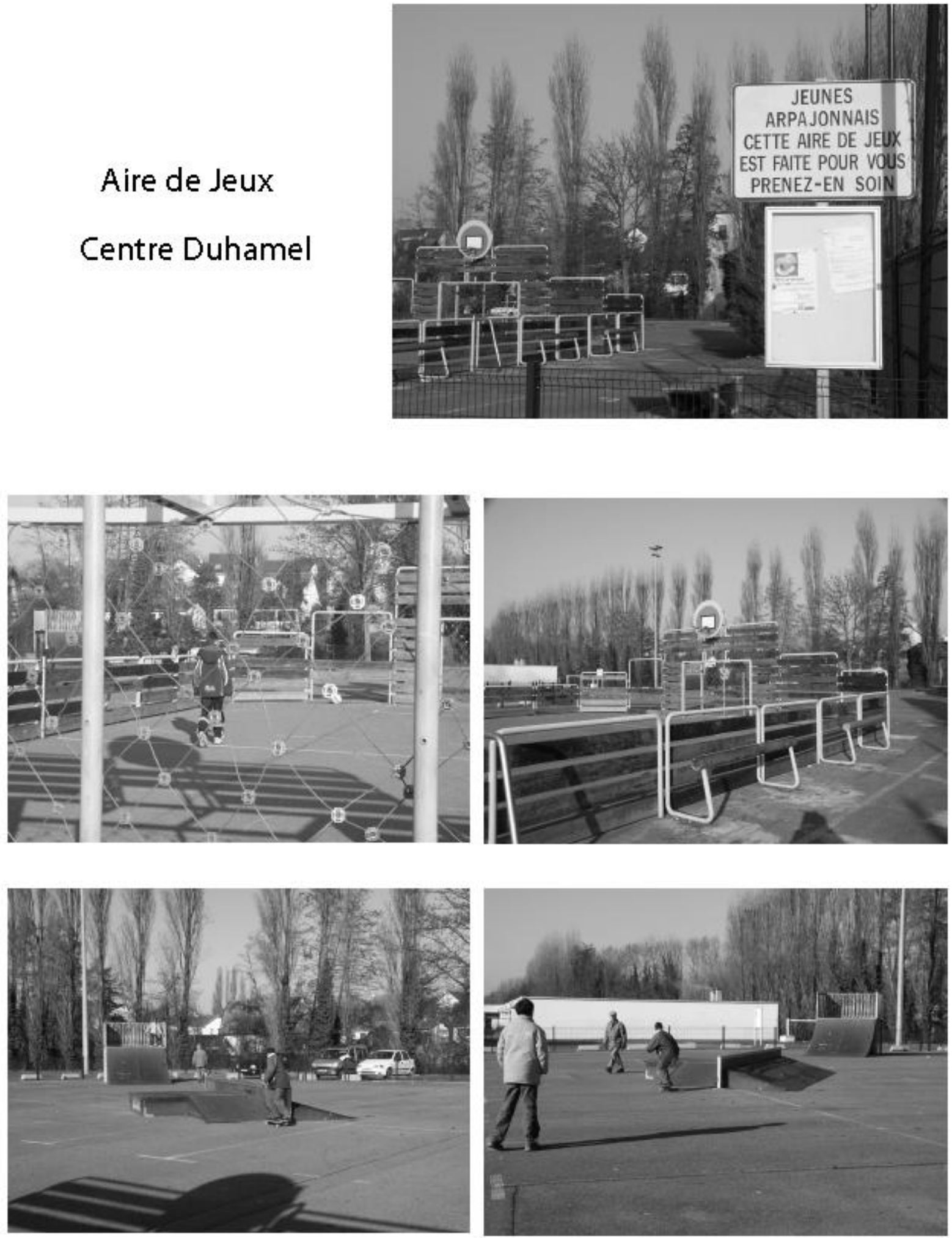

Note. For each place evaluated, the illustration plate presented to the children followed a strictly identical format to the one shown in the example. The name of the place was indicated in the heading on the left and five photographs were arranged in the same way. The original prints were presented in colour, with a $21 * 29.7 \mathrm{~cm}$ format. 
When the student responded that they did not know the place, the next plate was presented. If they did know the place, they had to respond to three additional questions. Firstly, they were asked how often they visited the place. The options were: "often", "sometimes" and "rarely". Then, they were asked if they visited it independently, in other words, on their own or with friends their own age without the company or supervision of an adult (parents, grandparents, teachers, brothers or sisters). Finally, they were asked if they had fun when they were in that place: "always", "sometimes", or "never". The purpose of this final question was to estimate the quality of the place as a recreational setting for the child.

\section{Variables and categories analyzed}

Based on the responses given to the questionnaire, four variables were defined.

1. Knowledge of the spaces, corresponding to the number of places the child stated they knew.

2. Independent access to the spaces, corresponding to the number of places the child stated they frequented alone or with friends, but without adults.

3. Frequency of visits, corresponding to the number of places the child stated they visited often or sometimes. This option allows us to differentiate between the spaces frequented rarely and those frequented more regularly, i.e. often or sometimes. In this case, it should be pointed out that the smaller children displayed difficulties differentiating between the options "often" and "sometimes".

4. Recreational use of the spaces, corresponding to the number of places where the child states that they always or sometimes play. Specifically, the aim was to define the recreational character that these spaces constitute for the child, drawing a distinction between the spaces where they stated that they played ("always" or "sometimes") and those where they declared that they never played. 


\section{Factors analyzed in the research}

The individual characteristics analyzed were gender (boys vs. girls) and age, categorized into six groups: $6,7,8,9,10$ and 11 years of age. The characteristics pertaining to living context were the type of housing in which the children live and the location of their homes in the town.

In relation to the type of housing, the responses of children who lived in individual houses were compared with those who lived in apartments. On the basis of their home addresses, a geographic information system (GIS) was used to locate the homes of participants in the town (geolocation process). This location process allowed us to distinguish between homes located in the lower part of the valley which are close to the town centre, and those on each slope of the valley, which are far from the centre. Hence, it was possible to compare the responses of the children who lived in the centre with those who lived in the outskirts of the town.

\section{RESULTS}

\section{Preliminary analysis}

An initial series of analyses was conducted to verify whether the children's responses presented significant differences according to each of the factors considered independently. In order to carry out these analyses, an ANOVA was used to compare the six age groups and Student's t test was used to study the gender component (boys and girls), type of housing (individual house vs. apartment) and for the location of the home (centre vs. outskirts).

The analyses show that no matter which variable is tested, there are no significant differences between the children in relation to the location of their home. Consequently, the factor «location of the home» was removed from subsequent stages of the analysis. In 
contrast, significant differences were found for one or several variables when comparing the responses according to the age sub-groups, gender or type of housing in which they lived.

This preliminary stage allowed us to refine the model of analysis used. Hence, a MANOVA was configured with a view to testing the main effects of these three factors as well as their interactions [Age (6) X Gender (2) X Type of housing (2)], on the four variables (knowledge of the spaces, independent access to the spaces, frequency of visits and recreational use of the spaces).

\section{Effect of the individual characteristics on the set of variables}

Table II indicates the average number of places that the children belonging to different sub-groups stated that they knew, accessed independently, visited regularly and used as a recreational space. The last column shows the results for the total number of children in the sample population.

\section{[Insert Table II]}

The children stated that they knew on average seven of the 10 places in the town presented in the questionnaire. We can consider the results concerning the other variables in reference to the 10 places in the town presented in the questionnaire, or in relation to the seven places which, on average, the children claimed they knew.

The children stated that they regularly visited half of the places presented in the questionnaire; however, the places visited regularly represented two thirds of the places that they knew. Table II shows that similar proportions are observed for the places the children claimed to play in. These results indicate that the children, through regular visits and recreational use, tend to appropriate the main outdoor public spaces of Arpajon. Additionally, we noted that as the children knew these spaces, they tended to appropriate the large majority of them. 
Table II Effects of the individual characteristics on knowledge and uses of public spaces

\begin{tabular}{|c|c|c|c|c|c|c|c|c|c|c|c|}
\hline & \multicolumn{6}{|c|}{ Age in years } & \multicolumn{2}{|c|}{ Gender } & \multicolumn{2}{|c|}{ Type of housing } & \multirow{2}{*}{$\begin{array}{c}\text { Total } \\
\text { sample } \\
\mathrm{N}=378\end{array}$} \\
\hline & 6 & 7 & 8 & 9 & 10 & 11 & Boys & Girls & apartment & house & \\
\hline \multicolumn{12}{|c|}{ Knowledge } \\
\hline Mean & 6.65 & 6.84 & 6.93 & 7.41 & 7.27 & 7.74 & 7.35 & 6.85 & 7.26 & 6.87 & 7.10 \\
\hline Test & \multicolumn{6}{|c|}{$F(5)=1.54$; n.s. } & $F(1)=$ & $=.020$ & \multicolumn{2}{|c|}{$F(1)=2.92 ; n . s$} & \\
\hline $\mathrm{Eta}^{2}$ & \multicolumn{6}{|c|}{.021} & & & \multicolumn{2}{|c|}{.008} & \\
\hline \multicolumn{12}{|c|}{ Independent access } \\
\hline Mean & 1.15 & 1.06 & 1.52 & 2.27 & 2.23 & 3.48 & 2.49 & 1.14 & 2.20 & 1.29 & 1.82 \\
\hline Test & \multicolumn{6}{|c|}{$F(5)=3.60 ; p=.003$} & $F(1)=2$ & $<.000$ & \multicolumn{2}{|c|}{$F(1)=14.92 ; p<.000$} & \\
\hline $\mathrm{Eta}^{2}$ & \multicolumn{6}{|c|}{.048} & & & \multicolumn{2}{|c|}{.040} & \\
\hline \multicolumn{12}{|c|}{ Regular visits } \\
\hline Mean & 5.10 & 5.43 & 5.36 & 5.62 & 5.12 & 5.94 & 5.78 & 4.99 & 5.75 & 4.89 & 5.39 \\
\hline Test & \multicolumn{6}{|c|}{$F(5)=.76$; n.s. } & $F(1)=1$ & $<.000$ & \multicolumn{2}{|c|}{$F(1)=14.92 ; p<.000$} & \\
\hline $\mathrm{Eta}^{2}$ & \multicolumn{6}{|c|}{.011} & & & \multicolumn{2}{|c|}{.040} & \\
\hline \multicolumn{12}{|c|}{ Recreational use } \\
\hline Mean & 5.13 & 5.19 & 5.09 & 5.62 & 5.07 & 5.45 & 5.54 & 4.95 & 5.47 & 4.93 & 5.25 \\
\hline Test & \multicolumn{6}{|c|}{$F(5)=.48 ;$ n.s. } & $F(1)$ & n.s. & \multicolumn{2}{|c|}{$F(1)=5.95 ; p=.015$} & \\
\hline $\mathrm{Eta}^{2}$ & \multicolumn{6}{|c|}{.007} & & & \multicolumn{2}{|c|}{.017} & \\
\hline
\end{tabular}

Note.- Mean: The means correspond to the mean number of places that the children in a specific age, gender or type of housing category claimed they knew, accessed independently, visited regularly or used to play. -Test: corresponding to interindividual tests for each of the four variables included in the MANOVA. - Eta ${ }^{2}$ are indices of the force of effects; they are considered low as of .010; intermediate as of .059 and strong as of .138 (Cohen. 1988). 
However, the results show that the children only access a small number of these places independently, in other words, without the presence of an adult accompanying them. In fact, in the town of Arpajon, children aged 6 to 11 visited fewer than two of the seven places they knew independently.

The MANOVA multivariate analysis tests indicate that Age and Gender, as well as Type of housing affect the set of four variables. The results of the tests are, respectively for Age: $(15-352)=2.46, p=.002$ and $\mathrm{Eta}^{2}=.034$, for Gender: $F(3-352)=8.67, p<.000$ and $\mathrm{Eta}^{2}=.069$, and for Type of housing: $F(3-352)=7.12, p=.002$ and $\mathrm{Eta}^{2}=.057$. The tests that correspond to the main effects were significant; however, the intensity of these effects is low. As shown by the Eta ${ }^{2}$ values, gender has the strongest influence on the children's responses, followed by the type of housing and, lastly, age. The tests carried out on the interactions between these three factors were not significant. This indicates that the global effects of a factor on the four variables are not modulated significantly by the effect of another factor. For example, the effects pertaining to the differences between boys and girls are not modified significantly according to the type of housing.

This next section analyzes in detail the effects of the three factors (Age, Gender and Type of housing) in relation to each of the four variables. Table II presents for each variable the tests conducted on the main effects of these three factors as well as an indicator showing the intensity of this effect $\left(E t a^{2}\right)$. It should be noted that in the univariate analyses and the multivariate analysis carried out, regardless of the variable studied, no significant interaction was observed between these three factors. For this reason, the results obtained for the interactions are not shown in Table II and will not be systematically examined below in the presentation of results.

Knowledge of the places 
Table II shows that the number of outdoor public spaces that the children claimed to know increases slightly with age, but the test is not significant. It is important to point out that the 6-year-old children already knew more than six out of the ten places presented. Only the 11-year-old children, who knew an average of 7.7 places, had a significantly higher score than the 6-year-old children, post hoc LSD test: $p=.008$. On average, boys knew a slightly higher number of places than girls; although small, this difference is significant. However, the fact of living in an individual house or an apartment block did not generate a significant difference in terms of the children's knowledge about the town's outdoor public spaces.

These results reveal an initial difference between girls and boys. However, we insist that during this stage of life, knowledge of outdoor public spaces evolves little according to age, since the 6-year-old children already possess good knowledge of the accessible places in their nearby urban environment.

\section{Frequency of visits}

The number of places that the children (boys and girls) claim to frequent regularly ("often" and "sometimes") does not vary according to age. Although Table II indicates that the 11-year-old children claimed to visit the highest number of places regularly, changes in the frequency of visits are not clearly related to age. In contrast, boys declare that they regularly frequent more places than girls, and the difference is significant. Furthermore, the places frequented regularly are significantly more numerous among children who live in apartments than those who live in houses.

\section{Independent access}

Analyzing the responses provided about independent access to outdoor public spaces leads us towards a first result: in Arpajon almost half (47.6\%) the children from the primary schools stated that they had never visited any of the 10 places presented alone or with friends. 
Table II shows that the number of places the children claim they frequent independently varies with age and the test is significant. Figure 2 provides a visual representation of this evolution between 6 and 11 years of age. Between 6 and 7, the number of places frequented independently is very low and remains stable. Furthermore, an initial change is noted from age 8 onwards, in other words, during their ninth year. Another stable period is observed between ages 9 and 10, and then another increase appears between 10 and 11. It should be noted that the number of independent visits among the group of 11-year-old children stands out from the rest of the sample population.

Figure 2 Evolution in the number of public spaces accessed independently according to age

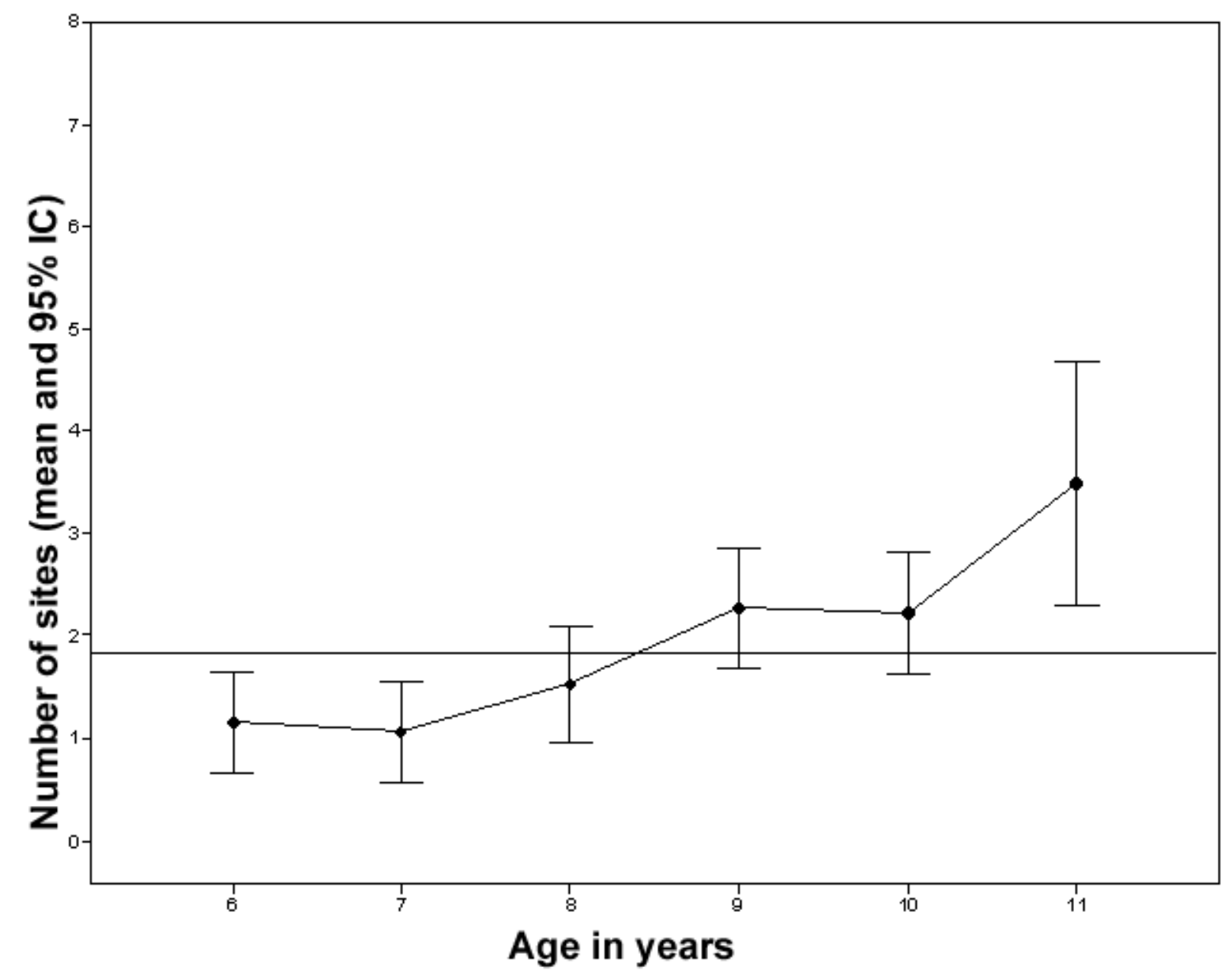


The results also show a significant difference between boys and girls. With an Eta ${ }^{2}$ higher than .059 , the effect of Gender on the independent access to outdoor public spaces offers an intermediate magnitude. This is the most important effect obtained from the set of results. Table II shows that boys claim to independently access twice as many outdoor public spaces than girls. Although the Age X Gender interaction is not significant, the difference between girls and boys tends to increase with age; in fact, the biggest difference is observed at age 11 .

Finally, children who live in apartment blocks present greater independent access to outdoor spaces than those living in individual houses, this difference being significant.

\section{Variations in the evaluation of the recreational character of public spaces}

The number of places where children state they "always" or "sometimes" play does not vary with age. Table II does not show any linear relations between age and the number of places used for recreational purposes. Specifically it is the 9-year-old children who claim to play in the highest number of places. Furthermore, no differences were observed as a function of gender, although boys appear to use a larger number of places as a base for their games than girls. However, children who live in apartments claim to play in a significantly higher number of outdoor public spaces than those living in houses. This difference is significant. 


\section{DISCUSSION}

The purpose of this empiric study was to specify the development of primary school children's knowledge and uses of the outdoor public spaces of their home town. The methodology employed allowed us to establish the degree to which knowledge and use of these places varies according to children's individual characteristics.

The results show that these six-to-eleven-year-old children claim to know most of the public spaces in their town. Moreover, the results also show that through regular visits and recreational use the children tend to appropriate of the majority of the places they claim to know. However, for children of this age range, the ways in which they use these outdoor public spaces do not entail independent access to them. In fact, although half of the children claim to have been alone or with friends their own age in an outdoor public space, these declarations only applying to one or two of the places studied. Therefore, it would be interesting to make further analyses to examine which social, spatial and physical characteristics of these places are likely to facilitate children's recreational use and independent access.

Analysis of interindividual differences reveals that knowledge and the type of use made of these spaces are modulated by the children's age, gender and type of housing. However, in the population studied, the effects of these factors, although significant, have a moderate impact.

Age. Examining in detail the role of age in the different variables, we note that this factor essentially affects independent access to public spaces. The number of places accessed independently by children increases between the ages of 6 and 11 . However, this increase is not regular or continuous; on the contrary, the development of spatial independence proceeds by stages which involve different phases of stability and growth. Hence, before the age of 8 , children possess practically no autonomy in their access to public spaces. An initial stage of 
acquisition of this independence emerges between the ages of 8 and 9, both for girls and boys. Then, a new phase of stability is observed, and subsequently a second phase of development emerges between 10 and 11 . This second phase is much more prominent among boys than girls. The increase in spatial autonomy between the ages of 8 and 9 has been observed in different environments, both urban and rural (MacDougall et al., 2009). This initial phase could be associated with the development of cognitive skills. In fact, several studies showed that 8-year-old children develop their capacity to geographically represent their everyday living space (Ramadier, and Depeau 2010). The second stage of development is equally welldocumented in the literature, where it is usually associated with the move from primary to secondary school, insofar as it implies changes in spatial practices. However, this argument cannot be used in the case of our study population. This second phase may be associated with an increased flexibility in parental prescriptions regarding their children's outings, which mostly apply to boys and to a lesser extent to girls.

The results also show that between the ages of 6 and 11, there is no significant variation in the number of regular visits, in the number of places used for recreational purposes or in the number of known places. Although it might be expected that children's knowledge of outdoor public spaces in their town would increase ostensibly with age, the results show that smaller children already know most of the parks, squares and play areas in their town. In fact, from as early as six, the children claim to know seven of the ten places presented. Such results mean that in a small town such as Arpajon, 6-year-old children already possess good knowledge about the public spaces and opportunities for outdoor play on offer in their town. New investigations should be carried out with younger children to ascertaining the starting age at which knowledge about public spaces emerges in urban contexts. 
Gender. Among all the factors studied, gender has the most significant effect on the ways in which outdoor public spaces are used. Differences were observed between boys and girls in terms of the number of places they knew, the number of places visited regularly and also in relation to the number of places frequented independently. In fact, the boys knew more outdoor public spaces than the girls, and visited a greater number of these places than them; this is particularly evident for the number of places visited independently. These results suggest that boys, in comparison with girls, have more opportunities to explore and use their nearby urban environment independently. However, the number of places that boys and girls claim to use for recreational purposes is similar. Beyond this observation, it would be interesting to determine whether these play areas are identical or different for girls and boys.

Type and location of housing. The type of housing in which the children live does not influence their knowledge about the public spaces in their town; however, it modifies the relationships established with them. Results suggest that children who live in apartment blocks make greater use of outdoor play resources available in the public space than children who live in houses. This is probably because children who live in a house have access to and can use a private garden. In fact, the children who lived in apartments stated that they played in a greater number of places than those who lived in houses; furthermore, they independently and regularly visited a significantly higher number of places than their peers. These results strengthen the idea that during childhood, certain elements that form part of the living environment contribute to shape the development of urban practices.

In contrast, no significant differences were found depending on the location (central vs. peripheral) of the child's home. Various studies have revealed that in France, neighbourhood and the socioeconomic status of the family are strongly correlated factors, with peripheral neighbourhoods usually corresponding to more working class areas (Tabard, 1996). However, in Arpajon a high degree of heterogeneity was observed in the status of 
housing both in the centre of the town and in the outskirts. In this respect, the comparison between central and peripheral sectors would essential imply an assessment of the effect of distance between the residence and the town centre, without implying an effective comparison of the socioeconomic status of the families. Furthermore, for the children, the apartment vs. house comparison would essential imply access or not to a private garden, rather than forming part of a social class. In effect, in Arpajon, houses are usually inhabited by middle and upper class families, but this category also encompasses working class housing estates dating back to the 60 s. Similarly, apartment blocks can be high-end or correspond to more modest blocks in estates. In this study, we did not have authorization to collect information regarding the parents' socio-professional status and level of education. For future studies, it is important to have access to this information in order to disassociate the effects of social and spatial factors on the urban practices of the children.

Limitations and perspectives. The interpretation of these results leads us to consider its limits. One limitation refers to the fact that the study was carried out in a small town in the Parisian Region. This implies that certain results might depend on the particular urban context of the study, specifically those pertaining to environmental factors such as the location of the home.

A second type of limitation that must be taken into consideration refers to the fact that the results are based on the declarations of children. In other words, they are behaviours stated by the children rather than observed behaviours. Consequently, these results accurately convey the children's representations of their urban practices, but they do not correspond necessarily to their actual practices. For this reason, in parallel to the approach presented in this study, we have also observed the behaviours of children in public spaces (Legendre, 2008). Furthermore, we have developed techniques based on GPS and a Geographic Information System (GIS) that allow us to record and analyze the positions occupied 
successively by children in the urban space (Enaux, and Legendre, 2010; Legendre et al., 2005). The combination of perspectives and methods which consider representations and behaviours at the same time may offer an improved understanding of the relationships developed by children with their nearby urban environment.

In spite of the limitations described, the results of this study have allowed us to examine the interindividual differences involved in the ways in which children aged 6 to 11 relate with the outdoor public spaces in their urban environment. The effects of age and type of residence were specified, and the major role played by gender difference has been highlighted.

\section{References}

Bachiri, N., Després, C., \& Vachon, G. (2008). Fighting teenagers' sedentarity: The challenges of mobility in exurbia. Medio Ambiente y Comportamiento Humano, 9 (1-2), 47-67.

Bagot, K. L., Kuo, F. E., \& Allen, F. C. L. (2007). Amendments to the Perceived Restorative Components Scale for Children (PRCS-C II). Children, Youth \& Environments, 17 (4), 124127.

Blinkert, B. (2004). Quality of the City for Children: Chaos and Order. Children, Youth and Environments, 14 (2), 99-112.

Bronfenbrenner, U., \& Crouter, A. C. (1983). The evolution of environmental models in developmental research. In P. H. Munsen (Ed.), Handbook of child psychology (Vol. 1. History, theory and methods, pp. 357-414). New York: Wiley \& Sons.

Burke, C. (2005). "Play in focus": Children researching their own spaces and places for play. Children, Youth and Environments, 15 (1), 27-53.

Cohen, J. (1988). Statistical power analysis for the behavioral sciences. Hillsdale: Lawrence Erlbaum.

Correa, N., \& Ruiz, C. (2008). Psicología Ambiental Evolutiva: construyendo un punto de encuentro. Medio Ambiente y Comportamiento Humano, 9 (1), 1-11.

Danic, I., David, O., \& Depeau, S. (Eds.) (2010). Enfants et jeunes dans les espaces du quotidien. Rennes: PUR.

Delalande, J. (Ed.) (2009). Des Enfants Entre Eux; Des Jeux, Des Règles, Des Secrets. Autrement.

Enaux, C., \& Legendre, A. (2010). Méthode d'identification des lieux investis par des enfants de six à onze ans dans leurs espaces de vie urbain quotidien. In I. Danic, O. David \& S. Depeau (Eds.), Enfants et jeunes dans les espaces du quotidien (pp. 89-100). Rennes: PUR.

Fjørtoft, I. (2004), Landscape as Playscape: The effects of natural environments on children's play and motor development. Children, Youth and Environments, 14 (2), 21-44.

Hillman, M., Adams, J., \& Whitelegg, J. (1990). One False Move: A Study of Children's Independent Mobility. London: Policy Studies Institute 
IAURIF (2003). Occupation du sol 2003 détaillée à a commune d'Arpajon 91021. Téléchargé le 07/01/2010, depuis http://sigr.iauidf.fr/amfphp/services/visiaurif/scripts/lite.php?idx=999\&layer=ficheCommunale\&function=d rawMos21AlphaScan

INSEE (2006). Résultats du recensement de la population- 2006: Tableaux détaillés. Téléchargé le 07/01/2010, depuis http://www.recensement.insee.fr/basesInfracommunales.action

Karsten, L., \& van Vliet, W. (2006a). Children in the City: Reclaiming the Street. Children, Youth \& Environments, 16 (1), 151-167.

Karsten, L., \& van Vliet, W. (2006b). Increasing Children's Freedom of Movement: Introduction. Children, Youth \& Environments, 16 (1), 69-73.

Larson, R. W., \& Verma, S. (1999). How children and adolescents spend time across the world: Work, play, and developmental. Psychological Bulletin, 125 (6), 701.

Legendre, A. (2008, 3-5 November). Role of Public Spaces in the Development of Children's Outdoor Games in a Suburban Town. Paper presented at the Child in the City, De Doelen-Rotterdam, The Netherlands. Téléchargeable sur http://conference.europoint.eu/childinthecity/presenation/Alain\%20Legendre.pdf

Legendre, A. (2011). Les lieux de jeux extérieurs des enfants d'âge scolaire : des espaces de proximité aux espaces publics urbains. Pratiques Psychologiques, 17, 31-48.

Legendre, A., Enaux, C., Depeau, S., Ramadier, T., Ferhat, G., Savina, Y., et al. (2005). Développement des pratiques urbaines au cours de l'enfance: Outils, méthodes et protocole pour une approche pluridisciplinaire (Rapport final No. 2002-10 Programme Société de l'Information, Action concertée incitative: Géomatique, Espaces, Territoires et Mobilité). Paris: Ministère de la Recherche et de l'Éducation - CNRS.

Lennard, H., \& Lennard, S. H. C. (2000). The forgotten child: cities for the well-being of children. International Making Cities Livable Council.

Lindstrand, P. (2005), Playground and Outdoor Play - A Literature Review. Stockholm: Stockholm International Toy Research Centre.

MacDougall, C., Schiller, W., \& Darbyshire, P. (2009). What are our boundaries and where can we play? Perspectives from eight- to ten-year-old Australian metropolitan and rural children. Early Child Development and Care, 179 (2), 189-204.

Meire, J. (2007). Qualitative Research on Children's Play: A review of recent literature. In T. Jambor \& J. Van Gils (Eds.), Several Perspectives on Children's Play. Scientific Reflections for Practicioners (pp. 27-78). Antwerp \& Apeldoorn: Garant Publishers.

Pedersen, D. M. (1999). Dimensions of environmental competence. Journal of Environmental Psychology, 19(3), 303-308.

Prezza, M. (2007). Children's Independent Mobility: A Review of Recent Italian Literature. Children, Youth \& Environments, 17(4), 293-318.

Ramadier, T., \& Depeau, S. (2010). Approche méthodologique (JRS) et développementale de la représentation de l'espace urbain quotidien de l'enfant. In I. Danic, O. David \& S. Depeau (Eds.), Enfants et jeunes dans les espaces du quotidien (pp. 61-74). Rennes: PUR.

Rasmussen, K. (2004). Places For Children - Children's Places. Childhood: A Global Journal of Child Research, 11 (2), 155-173.

Spencer, C., \& Woolley, H. (2000). Children and the city: a summary of recent environmental psychology research. Child: care, health and development, 26 (3), 181-197.

Spencer, C., Blades, M., \& Morsley, K. (1989). The child and the physical environment. Chichester: John Wiley \& Sons. 
Stone, S. J., \& Lozon, C. (2004), The cognitive and social values of play in the learning contexts of mixed-aged children. Paper presented at the 23rd ICCP World Play Conference, 'Play and Education', Cracow, 15-17 September 2004.

Tabard, N. (1996). Une représentation socio-économique du territoire. Paris: Données urbaines -Insee \& Anthropos.

Valentine, G. (2004). Public Space and the Culture of Childhood. London: Ashgate.

Vanderbeck, R., \& Johnson, J. (2000). "That's the only place where you can hang out": Urban young people and the space of the mall. Urban Geography, 21, 5-25.

Veitch, J., Bagley, S., Ball, K., \& Salmon, J. (2006). Where do children usually play? A qualitative study of parents' perceptions of influences on children's active free-play. Health \& Place, 12 (4), 383-393.

Wachs, T. D., \& Shpancer, N. (1998). A contextualist perspective on child-environment relations. In D. Görlitz, J. Valsiner, H. J. Harloff \& G. Mey (Eds.), Children, cities, and psychological theories: developping relationships (pp. 164-192). Berlin/New York: de Gruyter.

Witlox, F., \& Tindemans, H. (2006). Activity Patterns of Children and Youth in Ghent, Belgium: A Research Note. Children, Youth \& Environments, 16 (1), 133.

Wohlwill, J. F. (1980). The confluence of environmental and developmental psychology: Signpost to an ecology of development? Human development, 23, 354-358. 